\title{
Conjunções e disjunções entre comunicação e poética: alguns apontamentos
}

\author{
Gilson S. Raslan Filho (gilraslan@gmail.com) \\ Professor-pesquisador em Comunicação e Cultura; Professor do Mestrado em Desenvolvimento Regional da UEMG, \\ campus Divinópolis
}

\begin{abstract}
Resumo
É possível reunir poética e comunicação cotidiana e, assim, torná-las fenômenos não exclusivos? Este texto parte dessa questão e busca identificar os movimentos que possibilitaram a cisão. Assim, vê-se que, no esforço de superação da metafísica do pensamento moderno e contemporâneo, há a reafirmação da metafísica; na crítica a Platão, uma espécie de injustiça filosófica que retira de seu pensamento o elogio à poesia; na dissociação entre comunicação e poética a superfície visível desses equívocos. Assim, este texto é construído em arguir a razão por que houve a cisão, e em que medida tal separação traz em seu fundo a racionalidade e a razão centrada no sujeito, desde Nietzsche e seus seguidores até a tentativa de resgate da racionalidade por Habermas
\end{abstract}

Palavras-chave: Comunicação. Poética. Práticas cotidianas. Estética. Subjetivação.

\section{Conjunctions and separations among communication and poetic: some notes}

\begin{abstract}
Is it possible to gather poetic and daily communication and, like this, to turn them no exclusive phenomena? This text leaves of that subject and wants to identify the movements that made possible the scission. Like this, it is possible to notice that, when accomplishing the division, the metaphysics, denied by the modern and contemporary thought, it is reaffirmed; in the critic to Plato, there is a type of philosophical injustice that removes of his/her thought the praise to the poetry; in the dissociation among communication and poetic the visible surface of those misunderstandings. Like this, this text seeks to interrogate the reason why there was that scission, and in that measured the separation brings in his/her bottom the rationality and the reason centered in the subject, from Nietzsche and their followers to the one of rescue of the rationality undertaken by Habermas.
\end{abstract}

Key-words: Communication. Poetic. Daily Practices. Aesthetic. Subjectivity.

\section{Introdução}

Este texto é produto de inquietações que, senão se desenham como abduções apenas, indicam instantâneos, talvez por isso mesmo intempestivos. Porém, tal como se movimenta o 
pensamento, tais inquietações em torno de conceitos tão alienígenas entre si como comunicação e poética podem indicar uma certa piedade da razão e do próprio pensamento. Por isso, trata-se este texto de um instantâneo, que nem por isso, nem por ser talvez intempestivo, será destituído de razão. E assim, comunicação e poética, conceitos estranhos um ao outro (sendo um exógeno e o outro endógeno), não se estranham mais - pelo instantâneo: ambos se tocam na superfície, como quer a tradição nietzscheana: nada dessa tarefa de buscar profundidades imperativas - será na superfície onde a vida surge instantânea. Tampouco se trata de condenar a razão, mas compreendêla na dimensão da comunicação e da poética; não condená-la, mas compreendê-la na tessitura poética da vida cotidiana, que se faz em comunicação. Nessa medida e somente nessa medida, este texto poderá ser produzido e recebido.

Isso não implica dizer, agora contra a tradição nietzscheana, que a razão abandonou o mundo da vida; que todos os valores transmudados indicam a razão como uma despotencialização da vida, sua corrupção; nem mesmo que a intempestividade deste texto seja a sua condição de ser. Tornar a compreender a razão, sem no entanto fazer dela o bastião salvacionista, que marcou agudamente um dos principais vícios da primeira modernidade, é mister para o próprio desenvolvimento conceitual a que se propõe. Mas também não recusá-la, a razão, como categoria $a$ priori, igualmente, a rigor, salvacionista, o que seria admitir que a autorreferencialidade, condenada, da razão apenas foi recusada em sua pura negatividade, e isso é, tanto quanto os imperativos da razão, mais um imperativo. E então, a transmudação de todos os valores corrompidos torna-se a ilusão racional e o delírio dos valores.

\section{Aliterações da metafísica: pensamos apenas pés-de-página para Platão?}

Ainda que intempestivo, este texto irá procurar, pelo discurso racional, a distinção entre os conceitos propostos - e só então eles poderão ser tocados na superfície. De alguma forma, tentarse-á fazer justiça a Platão, acusado pelas escolas desconstrutivistas de ter expulsado os poetas de sua República. Platão só expulsa aqueles poetas que não se dignam à sua própria tarefa. Longe de condená-los por julgar sua arte decadente, duas vezes decadente, Platão apenas expulsa aqueles, ao contrário, que se julgam poetas por serem racionais somente. Escrevendo sobre o amor, em Fedro, Platão, pelo demônio socrático, diz: 
Existe uma terceira espécie de delírio: é aquele que as musas inspiram. Quando ele atinge uma alma virgem e ingênua, transporta-a para um mundo novo e inspira-lhes odes e outros poemas que celebram as façanhas dos antigos e que servem de ensinamento às novas gerações. Mas quem se aproxima dos umbrais da arte poética, sem o delírio que as Musas provocam, julgando que apenas pelo raciocínio será bom poeta, sê-lo-á imperfeito, pois que a obra poética inteligente se ofusca perante aquela que nasce do delírio. Essas são as vantagens do delírio que deriva dos deuses. Não devemos temer nem nos deixemos perturbar, pois, com um discurso no qual se pretende que se deva preferir, ao apaixonado, o sensato (PLATÃO, 1966, 223).

Mesmo que condenemos o discurso socrático, como o fez Nietzsche em sua apaixonada defesa do dionisíaco, por enxergar naquele discurso a manifesta moralidade transcendental, precisamos concordar que, em tal discurso, só há a condenação do poeta que se prende ao apolíneo. Isso de alguma forma joga dramaticamente a poesia no chão do cotidiano do mundo da vida, ainda que o delírio, a que se referiu Sócrates no diálogo, nos conduza para fora do cotidiano. É nessa medida que, posteriormente, a taxonomia aristotélica de Poética irá classificar a poesia como mais filosófica do que a história, por esta apresentar apenas o que ocorreu, enquanto aquela dizer do que poderia ser - diz-se do devir portanto (cf. ARISTÓTELES, 1992, 53).

Foi também nessa medida que Heidegger, buscando em sua virada metafísica a filosofia primeira, e também reivindicando a poética para um mundo da vida decaído, identificou a origem da obra de arte (HEIDEGGER, 1986). Em seu esforço por descobrir a essência do ser, como dasein, ser-aí, Heidegger viu como consubstanciação do ser-aí essencial o devir artístico, segundo o qual, em sua mirada ôntica, é apresentada ao homem sua condição finita de ser para a morte. Compungido pela decadência de um mundo da vida administrado, que esquecera a essência do ser, Heidegger, ainda que contemple o dasein no cotidiano, identifica-o, o cotidiano, como o mundo decaído, justamente aquele que encobre o ser, por esquecê-lo. A obra-de-arte então seria o lugar privilegiado onde a verdade da essência do ser é des-coberto; onde o tempo decaído do cotidiano administrado se temporaliza como origem em seu puro devir e como diferença.

A crítica radical realizada por Heidegger ao mundo da vida administrado passa pela crítica, ou, mais, pela condenação, seguindo os passos de Nietzsche, da própria razão - e não de uma racionalidade, simplesmente. O motivo pelo qual, segundo Heidegger, a essência do ser foi encoberto está no arruinamento sobreposto da metafísica ocidental, que estabelecia a razão suficiente como autorreferencialidade. Isso se tornara mais contundente, é verdade, como fenômeno da modernidade e pela virada metafísica kantiana. A razão iluminista foi anunciada, por Nietzsche, como o delírio da razão e, mais, como uma manifestação de decadência pela moralidade do mundo 
da vida. $\mathrm{O}$ advento do capitalismo sistêmico teria então aprofundado essa decadência. Nas palavras nietzscheanas, a racionalidade moralizada pela metafísica como dever-ser livre impôs ao homem o império da semelhança, ao prometer-lhe a saída da necessidade pela via da razão centrada no sujeito.

Heidegger foi adiante e identificou na crítica de Nietzsche uma persistência do encobrimento do ser pela metafísica justamente em seu conceito mais contundente: o eterno retorno - a que Heidegger acrescentou, para dar justeza ao seu raciocínio: do mesmo. A virada nietzscheana retirou da moralidade transcendental a autonomia dos homens e o reino da liberdade. A "gaia ciência" jogou os homens de volta à solidão potente e dionisíaca da realidade; antes contudo atacou violentamente a modernidade e seus planos de liberdade universal. No entanto, a vontade de potência foi identificada por Heidegger como a persistência da autorreferencialidade do sujeito centrado em si mesmo. Então houve a virada linguística patrocinada pelo pensamento heideggeriano: a linguagem é a morada do ser.

A analítica de Heidegger reconduz os entes jogados no mundo da vida para o descobrimento do ser essencial. Tal descoberta será efetivada pela analítica do ser, que rigorosamente é pela existência, ou seja, o ser-aí terá sua validade e compreensão justamente no mundo da vida, em que os entes são com e para o sistema de objetos e outros entes do mundo da vida. Todavia, o ser foi encoberto justamente por tal sistema. Cabe portanto à analítica procurar o ser esquecido no destino decaído do mundo da vida e de seus entes. Há um intricamento, mais, uma circularidade evidente na proposta heideggeriana: para realizar a virada metafísica e apresentar uma vertente pragmática para sua analítica, e desse modo retirar do sujeito sua autorreferencialidade, Heidegger apontou para a existência coletiva patrocinada pela linguagem: o destino do ente se abre pela linguagem no mundo da vida e é nessa abertura onde se encontra o ser-aí essencial. Diferentemente do centramento da razão no sujeito, a virada heideggeriana aponta para a existência ôntica da linguagem estruturada e sistêmica, como condicionantes do próprio conteúdo ôntico, mas também, por ser pela linguagem que o homem abre o mundo da vida, de sua superação na clareira transcendental do ser. Ao contrário do sujeito a priori ou da vontade de potência do super-homem que superou a metafísica, Heidegger propõe: os homens agem no mundo da vida imersos na estrutura sistêmica da linguagem, o que os torna unidos eticamente ao mundo, mas também lhes possibilita o escavamento para a descoberta da existência descorrompida. O ser-aí, então, habita a linguagem: por ela, e somente por ela, o sujeito poderá predicar-se - e é esse predizer a condição 
mesma do sistema tradicional da linguagem, que no entanto abre a potencialidade do mundo da vida como vir a ser. E, porém, justamente onde mora o ser, também ali ele se esconde pelo arruinamento do linguajear cotidiano. Enquanto ente para o mundo de objetos e com os outros entes, o homem que abre o mundo do devir e da diferença do ser poder-se-á corromper nas estruturas do mundo sistêmico do linguajear não poético. Trata-se então da pura negatividade, cuja representação clássica está no esquema comunicacional cristalizado - e ademais repetido pelo senso comum no cotidiano - como o esquema informacional.

\section{Tentativa: dos limites da informação à "virada" habermasiana}

Chegamos ao ponto de partida: enquanto há o primado do sujeito autorreferenciado, comunicação e poética se tornam indissociáveis, na medida em que os sujeitos racionais autônomos, iluminados, apenas se comunicam livremente para chegarem a acordos racionais; a diferença poética, o devir que só a poética poderá proporcionar, está ausente desse acordo - ao contrário, o esquema comunicacional-informacional deverá sempre tender ao mesmo: trata-se de entender o comum como o normal, como a extirpação da diferenciação, da différance, como quer Derrida (1995). A virada kantiana de Heidegger, no entanto, mesmo que tenha introduzido o mundo da vida e estruturado a linguagem como o espaço transcendental onde os homens se perfazem no ato de abrir o mundo pela linguagem, não resolveu a questão da diferença e do devir no mundo pelo ato de comunicação cotidiana. Por identificar a decadência do sentido do ser como a própria prática cotidiana; ao desvincular ser e ente, como bem notou Habermas (cf. 2000, 187-226), Heidegger apenas deslocou a questão da diferença para a crítica da modernidade e da racionalidade metafísica ocidental; ou, ainda, como disse Guattari (1992), Heidegger não conseguiu superar o ser-já-aí. Em outras palavras: ao desvincular ser e ente, a crítica heideggeriana não superou a metafísica do sujeito - ainda que seja constituído a posteriori, no mundo da vida e pela linguagem, deverão esses homens, num esforço analítico, descobrir a verdade do ser que está além do cotidiano e, portanto, além das práticas comunicacionais.

Antes de prosseguirmos será preciso entender a razão de a comunicação ser considerada um fenômeno que extirpa a diferença - ou, no mínimo, a impossibilita. A noção de entropia trabalhada pela teoria da informação fornece o elemento teórico que retira da comunicação, do ato comunicativo, ele mesmo, a possibilidade, senão estética, de subjetivação. Deve-se salientar: não se admite como primária, imediata mesmo, a relação estética-subjetividade. Há dimensões além da 
estética que definem os sujeitos ou, como queiram, os processos de subjetivação. O fato, porém, de as teorias da informação sequer terem entre suas miradas teóricas os processos de subjetivação, impossibilitarem qualquer voo estético e seguirem sendo adotadas como esquema teórico básico pela racionalidade administrada parece ser um fator preponderante o bastante para que se oponham poética/diferença e comunicação/semelhança. Seja como for, a dicotomia está em seu cerne teórico: segundo aquelas teorias, caso não haja um código normatizador que imponha ordem a uma série infinita de informações, desorganizadas em probabilidades infinitas de organização, não haveria qualquer possibilidade de entendimento e, assim, da própria comunicação. A estrutura dos signos sejam eles linguísticos ou não - é útil, nesse sentido, não apenas para impor ordem, mas para impossibilitar ao máximo o erro e o ruído. Assim, a produção de sentido compartilhado é codificada severamente, e tal sentido só é quebrado, de dentro da codificação, pela prática poética, que, pela expansão semântica, leva as informações a um curto-circuito que tende ao retorno à fonte entrópica (WEAVER, 1971; também: JAKOBSON, 2001).

Parece claro, para além da disjunção entre os "fenômenos", que as teorias da informação - traduzidas como teorias da comunicação - se tornam o lugar privilegiado para o florescimento, nas ciências do espírito, da racionalidade instrumental administrada, contra a qual se insurgiu a analítica de Heidegger. Nesse caso, a analítica heideggeriana só faz cumprir essa impossibilidade da comunicação cotidiana no mundo da vida em descobrir o sentido do ser. Assim, pode-se chegar a duas conclusões: ou bem Heidegger desenvolveu seu pensamento crendo naquela associação inextrincável entre informação e comunicação; ou bem aponta para esse sentido do ser em uma esfera metafísica; o seu ser-aí não avança para a virada linguística, como quis crer, e sua essência do ser implica uma anterioridade do ser e uma decadência do cotidiano.

É justamente esta a crítica de Habermas a Heidegger: a permanência na metafísica que este se esforçou em desmontar. A teoria habermasiana da comunicação promete deslocar a problemática novamente para o seio do mundo da vida - o cotidiano histórico, bem dito constituído e constituinte de todo ato comunicativo, em que atores linguisticamente atuantes agem em torno de proposições e acordos válidos. Nessa medida, Habermas de fato consegue substituir a categoria do ser, isolado de entes que são lançados no mundo da vida, por uma verdade que a um só tempo é factual e validada pelos acordos.

Todo o esforço de Habermas, no entanto, é envidado na defesa da racionalidade e de um projeto, por ele julgado inacabado, da modernidade (HABERMAS, 2002). É nessa medida que sua 
teoria da ação comunicativa, sustentado em uma imputabilidade da razão entre os atores em busca do bem comum e da liberdade, desloca a racionalidade do sujeito para a própria ação comunicativa. Também é nessa medida que Habermas faz uma longa crítica a Nietzsche e aos que considera os seguidores de seu pensamento, de Heidegger a Foucault.

Sua defesa da ação racional em um mundo comunicativo, porém, desloca e impossibilita mais uma vez a associação entre a comunicação e a poética em seu fazer da diferença. Mesmo que a teoria habermasiana diga, com razão, que a racionalidade não implica a extirpação da possibilidade da diferença, é inegável que as categorias da razão, tal como as categorias da informação codificada na comunicação cotidiana, se sustentam em formalidades e imperativos, que são justamente os acordos de validade e a imputabilidade do agir comunicativo. Ainda que, como de fato ocorre com a poética em relação ao código linguístico ou ao sistema simbólico, haja possibilidade do surgimento da diferença propriamente poética no agir comunicativo, ainda assim, a racionalidade comunicativa, por ser necessariamente normativa, tende não à individuação, como ele quer, mas ao ensimesmamento, em que os discursos se diferenciem apenas formalmente; em que atores se fecham em células onde possam, sem riscos, ter seu acordo cumprido.

Ainda assim, é notável o esforço de Habermas para compreender e retomar a tarefa hegeliana, de erigir a ética, como uma unidade/totalidade espiritual entre os humanos, sobre a racionalidade, agora desmistificada de sua autorreferencialidade, um vício, digamos, positivista e neopositivista (cf. HABERMAS, 2000, 35-108). É justamente em função da quebra da racionalidade comunicativa que o mundo foi cindido entre o mundo da vida e o mundo sistêmico, que tem no capital sua sustentação de autorreferencialidade, em que a racionalidade não se efetiva; em que a razão se mitifica; e por fim em que, justamente em função da ausência da razão comunicativa, a ética não se cumpre. A crítica habermasiana aos pós-nietzscheanos, sobretudo aqueles identificados com o desconstrutivismo, indica apenas uma crítica do combate à razão e à modernidade empreendida por eles.

\section{Considerações finais}

Mesmo que seja contundente e pertinente a crítica, sobretudo aquela que diz respeito à saída da modernidade e da razão, será preciso compreender o conceito de heterogênese desenvolvido especialmente por Guattari. Também ele, como ademais os pós-estruturalistas, percebeu, juntamente com Heidegger, a virada da linguagem para a compreensão da subjetividade. 
Como Foucault, Guattari se recusa a pensar o sujeito, mas somente em subjetivações, que se perfazem no jogo de heterogênese, em que o devir se apresenta a todo momento. No entanto, mesmo os pós-estruturalistas se recusam a admitir a diferença no seio do processo comunicacional cotidiano. Ainda que Guattari faça surgir, com sua heterogênese, as subjetividades no processo de sociabilidade, ainda assim da comunicação cotidiana é retirada a possibilidade de que curtoscircuitos criativos se realizem. Essa recusa, também para Guattari, se dá baseada no princípio normativo da comunicação, que impossibilitaria os devires da subjetividade. Porém, se por um lado, o conceito de heterogênese dá uma resposta satisfatória à problemática indefinida pela ação comunicativa de Habermas, por outro, não é possível recusar a hipótese de que a racionalidade é um preceito categorial da existência humana no mundo da vida. Acordos de validade são tão necessários para o mundo da vida quanto são improváveis que esses acordos se limitem à racionalidade sem se transformarem em homogêneses.

A prática cotidiana da comunicação compreende dessa forma tanto os acordos de validade quanto a necessária polifonia do mundo da vida. Se se quer empreender de fato a tarefa ética pela diferença e pela subjetivação, será preciso não perder de vista que as práticas comunicativas cotidianas são, mais do que capazes, conduzidas pelo próprio mundo da vida e da intersubjetividade a curtos-circuitos de sentido, que, à maneira da taxonomia aristotélica, indicam para o que pode ser.

Parece claro, no entanto, que a razão de ser da ação comunicativa e da heterogênese aponta para outro lugar que não o mundo degradado do capitalismo. De fato, esperar da prática comunicativa cotidiana esses curtos-circuitos poéticos é uma postura, senão conformista, certamente idealista. É justamente por haver necessidade de ações efetivas, que não contemplem apenas racionalidade, mas razão e delírio para o mais além - justamente por isso, e porque os veículos de comunicação fazem parte do grandioso maquinário de sustentação do mundo sistêmico e corroído do capitalismo, que cabe aos especialistas nesse maquinário comunicacional a tarefa de possibilitar, pelo próprio maquinário, que a comunicação cotidiana se cumpra como uma racionalidade poética - e nessa medida, que a razão se arrazoe, como quer Habermas, e se arrazoe tanto que permita o pensamento além da razão autossuficiente. E então, na superfície intersubjetiva, o mundo da vida fará de Platão uma presença constante, a ponto de poder, enfim, superá-lo - pois concluirá que ele não expulsou o poeta de sua República - apenas os falsos poetas que hoje 
alimentam o sistema que se auto-alimenta, num jogo de espelhos que o estende ao infinito, a ponto de não deixar ver os sujeitos, suas racionalidades, seus delírios.

\section{Referências}

ARISTÓteleS. A poética. São Paulo: Ars Poética, 1992.

DERRIDA, Jacques. A escritura e a diferença. São Paulo: Perspectiva. 1995.

GUATTARI, Felix.. Caosmose - Um novo paradigma estético. Rio de Janeiro: Editora 34. 1992

HABERMAS, Jürgen. O discurso filosófico da modemidade. São Paulo: Martins Fontes. 2000.

HABERMAS, Jürgen. Agir comunicativo e razão destranscendentalizada. Rio de Janeiro:

Tempo Brasileiro. 2002.

HEIDEGGER, Martin. A origem da obra de arte. Revista Kriterion. Belo Horizonte: UFMG, v XXVII, n 76, p. 185-210, jan/jun, 1986.

HEIDEGGER, Martin. Ser e tempo. Petrópolis: Vozes. (2v) 1993.

JAKOBSON, Roman. Linguística e comunicação. São Paulo: Cultrix. 2001.

PLATÃO. Diálogos: Mênon; Fedro; Banquete. São Paulo: Edições de Ouro, 1966

WEAVER, W. A teoria matemática da comunicação. In: COHN, Gabriel. Comunicação e

indústria cultural: leitura de análise de meios de comunicação na sociedade contemporânea e das manifestações de massa nessa sociedade. São Paulo: Cia Editora Nacional; Editora da USP, 1971. 